\title{
Erratum
}

\section{Donor patterns: a modular structure for sharing knowledge}

Alan Jessop, David Parker (Oakdene Hollins) and John Temple (Consultant)

Journal of the Operational Research Society (2015) 66(11), 1948. doi:10.1057/jors.2015.57

Published online 8 July 2015

Correction to: Journal of the Operational Research Society (2015) doi: 10.1057/jors.2015.31

Published online 13 May 2015

We regret that David Parker's affiliation was originally misspelled in this paper. We would also like to apologise for the erroneous typesetter logo that was accidentally left on page 12. This has not affected the research in any way.

No other element of the paper is under question. 